أبحاث المؤتمر العلمي الدولي الثاني / نقابة التمبية

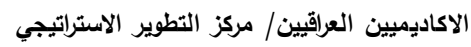

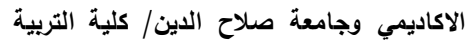

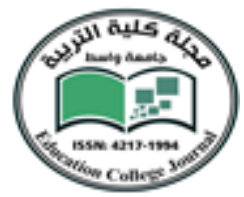

جامعة واسط

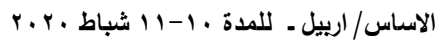

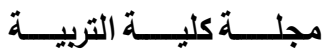

\title{
The Function of Subordination in Creating Effective Speeches
}

\section{Asst. Inst. May Tahseen Hameed Diyala University-College of Education for Humanities maytahseen14@g.mail.com}

\begin{abstract}
The aim of the study is to investigate subordination as an important tool in effective speeches and to find out the role they play and if it enhances theirmeaning . A sample of two speeches were chosen to show which type of subordination is most prominent, writers uses subordination as a feature for their language they have a message they want to deliver, speakers also do . The model of the analysis is guided by functional grammar of Halliday (2004).Subordination is the grammatical arrangement of functionally similar but unequal constructs in a complex sentence as Fish defines it (2011:51). It creates strong pauses, writers use subordination when they want to give logical, causal or temporal relationships within clauses so in writing it is used effectively as a device for persuasion and argument,speakers also needs to be arguers and persuasive .
\end{abstract}

Keywords :subordinators, logical relation, grammatical complexity ,functional. 
أبحاث المؤتمر العلمي الدولي الثاني / نقابة التمرئ

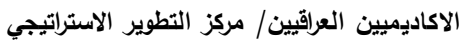

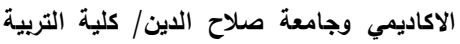

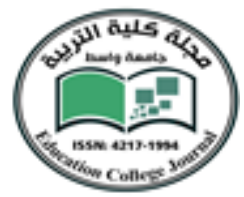

جامعة واسط

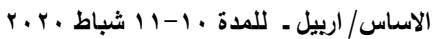

ة

\section{Introduction:}

The notion of clause complex as proposed by Halliday(Halliday \&Matthienssen,2004:8) is that a sentence can be interpreted as a clause complex :a Head clause together with other clauses that modify it .He further states that a combination of clauses related and ,the mode of combination is the mode of organization of the logical subtype of the ideational meta function .He argues that the notion of clause complex' thus enables us to account in full for the functional organization of sentences (Ibid:216).Eggins (2004,255-6) mentions that the term "clause" itself is called clause complex . In formal grammar clause complex equals complex sentences .Morley $(2000,70)$ also states that a preferred term when discussing units of grammatical form would be (clause complex), which is defined as the logical grouping of clause units around at least one main clause and in any configuration .

In systematic Functional Linguistics inter-clausal relations or logicosemantic relations consists of coordination and subordination Halliday states that subordination is a logical interdependency between clauses where the interdependent are of unequal states(2004:216) .In other words it is where one part of relational schema is more prominent than the other part, within every unit in meaning structure some elements are more prominent than others, either the antecedent is dominant or the consequent is dominant.

To some extent, the notion of clause complex is used in place of the traditional notion of sentence when referring to the logico-semantic unit above the clause because it enables further analysis of the spoken and written speech .A clause complex is made up of clauses. The complexes are developed link by link. The nature of these links is determined by taxis and logico function enables a clause complex to "go on" linearly as much as the speaker wants .At the semantic stratum,texts are organized as rhetorical complexes -passages are linked through rhetorical relations .

How clause complexes are constructed from clauses is that people in their use of language, in many cases ,tend to expand their arguments outwards by 
أبحاث المؤتمر العلمي الدولي الثاني / نقابة

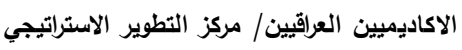

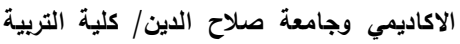

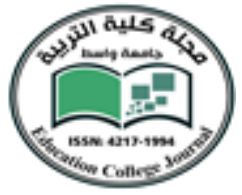

جامعة واسط

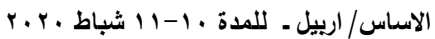

مجلـــــة كليــــة التربيــــة

combining ,or complexing the original clause with other related clauses into series of clauses with the main clause as the core of the message and the coordinate or subordinate clauses as the peripheral information added to reinforce the message. People in many cases use language to describe not only the non-linguistic phenomena but also report or quote the linguistic phenomena as well, allowing the reported or quoted clauses to enter into a combination of clauses as the projected part in the whole combination - the secondary use of language .All complexes are structured as series of related elements : each relation represents a new expansion of the complex .The complexes are developed link by link ;each pair of linked element is called a nexus.Halliday and Matthienssen $(2004,373)$.

There are two systems involved in the formation of clause complexes .One is Tactic system or interdependency and the other is Logico-semantic relation. When we put many clauses together ,the meaning is strengthened as pointed by Halliday (Ibid,2004,373) .Semantically ,the effect of combining clauses into a clause complex is one of tighter integration in meaning. In the clause complex - clauses linked together by logico - semantic relations to form sequences (Ibid,2004:61) . In accordance with this Parrott(2004:389) emphasizes that: "We generally put the clause which contains any information we can take for granted first. The clause which contains the new or more important information generally comes second".

Subordinating is defined by Halliday(Halliday \& Matthiessen,2004:384) as the binding of elements of unequal status .The dominant element is free , but the dependent element is not . subordinating conjunctions indicate the relation between clauses, as explained by Qurik et al (1985:987), it insists on hierarchy as it creates strong pauses, letting subordinate conjunctions put twists and turns into a sentence allowing the movement from one group of idea to another. The subordinating construction is the argumentative construction .Writers use subordinators when they want to convey logical, causal relationships within the clauses .It is used effectively as a device for argument and persuasion and to express individual and related thoughts by 
أبحاث المؤتمر العلمي الدولي الثاني / نقابة

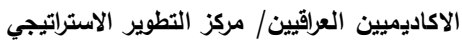

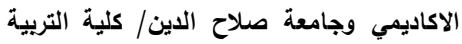

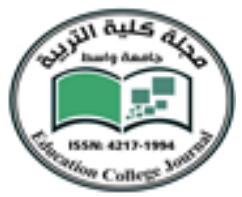

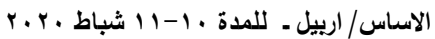

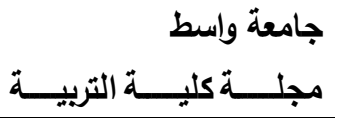

using subordinate clauses. The subordinate clause helps to amplify a central idea .

We use markers to show the relationship between each clause ( words like because, when ) and we also use the spoken language systems of rhythm and intonation to signal to our listeners that we have reached the end of a clause sequence ,as remarked by Eggins(2004:255),So subordinating is concerned with the binding relationships between units of clauses of unequal statues ( e. g. $\beta$ and $\gamma$ ) as stated by Morley(2004:87) , using the Greek letters for the purpose of the analysis, a conjunction bearing clause called dependent clause $(\beta)$ rests on another clause called dominant clause $(\alpha)$. Eggins $(2004,261)$ states that subordinator is generally more common in written text because dependency relations require the writer to be careful enough so as to construct and require more effort by readers to interpret hierarchic organization of information demanded by subordinating also offers the writer resource for offering more closely controlled logic between events. Subordinator signals the logical or temporal relationship between clauses .It creates strong pauses, also it helps in making clear what the readers should be focusing on, it helps in giving the text special focus and an emotional touch In writing it allows the writer to maintain a very congruent style, as the writer exploits the strategy of grammatical complexity (Eggins, 2004:273) .

\section{The model of analysis:}

The research mainly refers to Halliday And Matthiessen (2004) since this is the most comprehensive and authoritative description of English lexico semantic and grammatical relationships, it is the model on which the analysis is built.

\section{Logico-Semantic relations:}

The analysis focuses on the resources which the writer/speaker establishes "logical " relations between clauses and between clause complexes -relations, which Halliday has divided into those of projection 
أبحاث المؤتمر العلمي الدولي الثاني / نقابة التمرئ

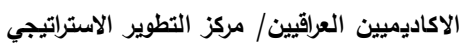

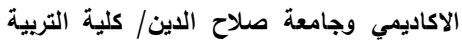

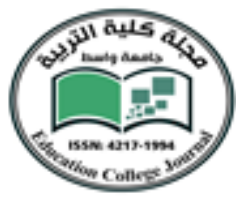

جامعة واسط

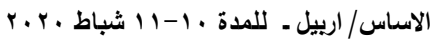

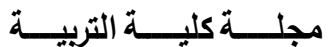

and expansion and within expansion, into extension, elaboration and enhancement (Halliday and Matthiessen,2004). They are the means by which the interconnected "logic " of texts is built up. The logical relation has been expressed through a conjunctive word or expression ,Eggins(2004:257).The clauses are either superordinate $(\alpha)$ which is a free clause, or subordinate $(\beta)$ which is a bound one.(Halliday and Matthiessen,2004:170; Morley ,2000;84). The tactic structure of complexes are relational in nature. They are the kind of structure that we have called univariate ,to distinguish it from multivariate structures .Halliday and Matthiessen(2004:383),Eggins(2004). This principle is that the different metafunctional modes of meaning tend to be realized by different structural modes one of them is subordinate which includes mode of structure (iterative), and of meaning (logical) .

The lexico grammatical system named logico - semantic type organizes clauses according to the ideational relation between them ,this relation can be either projecting or extending. They are considered semantic domains (Halliday and Matthiessen,2004:377). Each clause in a clause complex is a realization of a figure, a move and a message.By using lexico grammatical relations, it builds several dependent clauses upon one another forming one complete thought, if you want the reader to stay sharp, alert and keep up with your story, With complexity you make people think more about what you said. Projection corresponds to verbal and mental clause and expansion corresponds to relational clauses, Ibid(2004:367).

Halliday emphasizes that in this structure, the elements are ordered in dependence, and this ordering is largely independent of the sequence (ibid:387).Here is an explanation of each one of logico-semantic relations .The secondary clause is the dependent one which can either precede the dominant clause $(+\beta \alpha)$ or follow it $(\alpha+\beta)$.

1) Expansion : As divided by Halliday (Halliday and Matthiessen ,2004) the secondary clause expands the primary clause by :

a) Elaborating :one clause elaborates on the meaning of another by specifying or describing it .The secondary clause dose not introduce a 

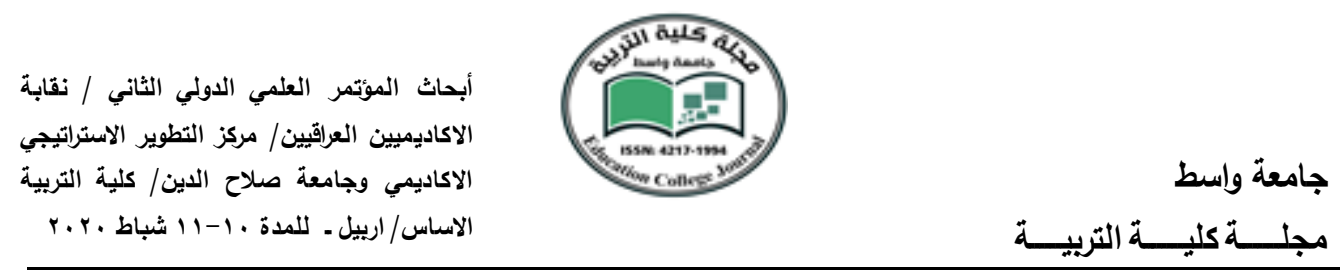

new element into the picture but rather provides a further characterization of one that is already there, restating it ,clarifying it, refining it or adding a descriptive attribute or comment . Notation $(\alpha=$ $\beta$ ), (alpha = beta) gives the category of non-defining relative clause it is as a kind of descriptive to the main clause introducing into the discourse background information .

b) Extension :one clause extends the meaning of another by adding something new to it ( Halliday and Matthiessn:405;Eggines,2004:234) either as addition or replacement or an alternative ,notation $(\alpha+\beta)$ Halliday states that the dependent clause may finite or non-finite. The extending clause is dependent and may be finite or non-finite form with alteration the dependent clause comes first.

c) Enhancement : in enhancement one clause (or sub complex) enhances the meaning of another by qualifying it in one of a number of possible ways : by reference to time ,place, manner ,cause or condition (Halliday and Matthissen,2004:410;Hasselgard,2010:140)

Notation $(\alpha \times \beta)$, enhancement can be either finite or non-finite, gives what are known in traditional formal grammar as "adverbial clauses" as mentioned by Halliday.Halliday and Matthiessen (2004:41022)provides extensive examples and discussion of all the sub types which are not going to be mentioned here for limitation of space.

The second type is projection, unlike expansion there are no conjunction marking relations of reporting according to Halliday (Halliday and Matthiessen,2004:377) .

2) projection is the secondary clause projected through the primary clause which instates it as a) a locution or b) an idea .Expansion relates phenomena as being of the same order of experience, while projection relates phenomena to phenomena of a higher order of experience (semiotic phenomena what people say and think).Locution [“" (double 
أبحاث المؤتمر العلمي الدولي الثاني / نقابة التمبية

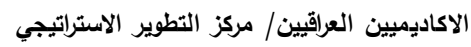

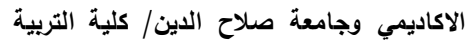

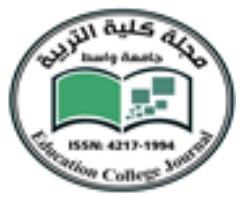

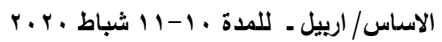

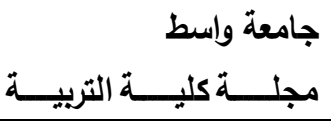

quotes )] and idea ['(single quote)].Locution(says)as defines by Halliday "one clause is projected through another, which presents it as a locution(Ibid,2004:) a construction of wording .Idea (thinks) one clause is projected through another, which presents it as an idea, a construction of meaning .

In spoken language tone and intonation play the role of punctuation to give the meaning of sentences .Halliday mentions (ibid:61) that the clause depends on prosodic features -peaks of prominence located at beginnings and endings.Finally, it is worthy to mention what Halliday named anaphoric ellipsis (ibid:100) ,some part of the clause is presupposed from what has gone before sometime the anaphoric reference item is the relative(ibid:397). It is important to mention that Subordination is what give the speech emotional impact and force and brings the hearer's attention to what follow the subordinator.

\section{The corpus of analysis:}

The research aims at analyzing the speeches of two of well known influencers in the world, those two are :Steve Jobs and Bill Gates. The speech of Steve Jobs delivered to the graduates of Stanford University in 2005, and of Bill Gates in his commencement speech in the graduation sermon in 2007 he is a remarkable man and a great philanthropist. The speech of Steve Jobs is inspiring It is structured in the most simplified way with an underlying theme and flawless use of rhetorical devices. His style is famous for being simple and clear he uses traditional structure and he tries in his speech to inspire and convince .He is recognized for his brilliant speaking abilities .

The researcher is going to choose some sentences from both speeches because of space and time limitation. Because subordination is realized mainly by subordinate clauses. subordination is used by people to achieve cohesion in text .These speeches are very long and are full of different types and lengths of clauses and clause complexes so they are enough 
أبحاث المؤتمر العلمي الدولي الثاني / نقابة

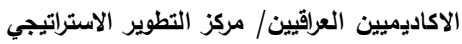

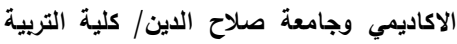

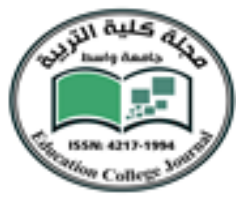

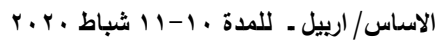

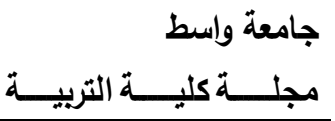

samples to demonstrate the core purpose of this research and to fulfill its aim.

We need to mention that the secondary clause is in tone concord with the primary clause that constitutes its domain 4-4-1 (Halliday and Matthiessen ,2004:402) .The tone selected for the relevant portion of the primary clause is repeated in the secondary clause, Chafe elaborated on that by saying that those idea units that finish with arising intonation should be marked with a comma while the ones that end with falling intonation are indicated with a period intonation is the key to separate idea units .(Chafe,1980:14;Hasselgard ,2010:94) .

Subordinate clauses as mentioned by linguists ( Morley ,2000:83; Qurik et al ,1985 :1006; Collins ,1991:27; Ahenberg and vago;2010:96) which have this type of role as the bound clause will respond to the question words and phrases: who? ,What? , When ?,Why?,How?, When?, Where?, Which ?, in what circumstances ?,etc., which , when added to the subordinate clause may be targeted at the bound clause.

\section{Analysis of the data}

Now we come to the analysis of some selected clauses from the speeches under study. This symbol $(\mid)$ is used to show sentence's boundaries, and this one $(\|)$ is to show clause boundaries.

Sample number

(1) II dropped out of Reed college( $\alpha) \|$ after the first 6 months( $\beta) \|$ but then stayed around as a drop - in $(\gamma) \|$ for another 18 months or $\operatorname{so}(\delta) \|$ before I really quit $(\grave{\varepsilon})$ |

Here (after) in the secondary dependent clause ( $\beta$ )this clause is immediately bound to (I dropped out of Reed college ) expressing an enhancement temporal relation with it, this bound clause is non- finite. The bound to $(\gamma)$ clause and this is bound to $(\delta)$, and this is bound to $(\grave{\varepsilon})$, the $(\beta)$ and the $(\grave{\varepsilon})$ clauses answer the question :when did I quit? Halliday mentions that in a 
أبحاث المؤتمر العلمي الدولي الثاني / نقابة

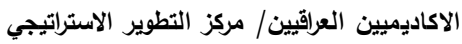

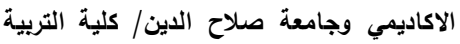

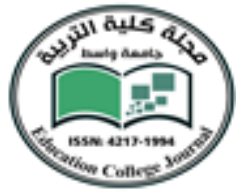

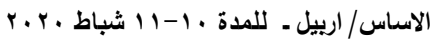

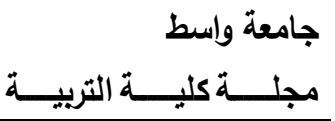

subordinate structure the elements are ordered in dependence and this ordering is largely independent of sequence .Halliday and Matthiessen(2004,387) this is called a chain of nexus, the speaker chooses this additional subordinating conjunction elements to make the speech more fluent and easier to follow and more sophisticated, Quirk et al(1985) named this kind of relation (embedded clauses ) and ( part to whole ) relation and this relation gives rise to the theoretical possibility of grammatical units having indefinite length .In the subordinating chain as Halliday calls it ,each new link in the chain moves further away from the place in the discourse where the dominant clause is located .

(2) | It started $(\alpha) \|$ before I was $\operatorname{born}(\beta)$ |

Here (before) is a subordination because it introduces a finite clause .Greenbaum and Nelson(2002:112) .(before I was born )is a non - finite subordinate clause shows a temporal relation, that some event happens before another event, here we have enhancement .The speaker uses past simple tense in the second clause to refer to event in the past., he wanted the hearer to focus on the time of the starting of the event.

(3) IShe felt very strongly $(\alpha) \|$ that I should be adopted by college graduate , ( $\beta) \|$ so everything was all set for me $(\gamma) \|$ to be adopted at birth by a lawyer and his wife $(\delta)$ ।

The relative pronoun (that) expresses an elaboration, this nominal clause ( that I should be adopted by collage graduate ) is an "attributive" or relative clause qualifying nouns Qurik et al.(1960:324) .Here is the pronoun (she)which is called antecedent, the adjective clause is a necessary part of the idea if it is left out the sentence, it doesn't make complete sense .Here it seems reasonable to claim that the subordinate clause represents supporting information that should be taken for granted. The secondary clause doesn't introduce a new element into the picture by rather providing a further characterization of one that is already there, restating it, clarifying it , 
أبحاث المؤتمر العلمي الدولي الثاني / نقابة التمرئ

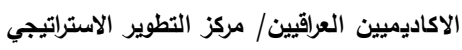

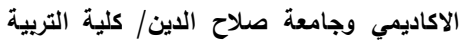

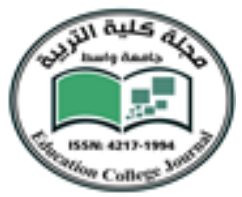

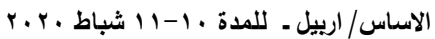

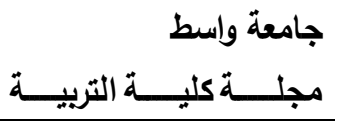

refining it , or adding a descriptive attribute or comment ,( Halliday and Matthiessen ,2004,396) .It is a kind of gloss to the primary clause ,there is obligatory anaphoric reference item ,the relative .This is a special clausal construction as stated by Halliday (2004:397). The second secondary clause starts with (so) which is an enhancement clause (or sub complex). It shows cause and effect reason lpurpose relation .

In this clause complex we can see that there are two sub types of logicosemantic relations :explanation including elaboration and enhancement, it is possible to have such cases. This plays a role in reinforcing the intension of the speaker in delivering his message to his audiences .

(4) I I didn't have a dorm room, , $\alpha$ ) \| so I slept on the floor in friends' $\operatorname{rooms}(\beta)$ |

(so ) in the dependent clause shows enhancement of result, it is a finite clause .In a complex sentence like those sentences above there one main idea and one or more subordinate ideas, as marked by Alexander(1990:10) and other linguists.

(5) | Remembering that you are going to die $(\beta) \|$ is the best way I know $(\alpha)$ $\|$ to avoid the trap of thinking $(\gamma) \|$ you have something to lose $(\delta) \mid$

The relative clause is showing elaboration ,.Here ,the dependant clause precedes the main clause and it is enclosed because the nominal group is nonfinite in the primary clause .(Halliday and Matthiessen,2004:401).The verb (know ) shows a projection of idea - thinking it is a mental process (cognitive), the word( thinking )also is the same .Jobs uses a relative clause to add more explanation (remembering what?)then he uses projection of idea to emphasize the idea of remembering, and bearing in mind that one may die at any moment. Here there is a (that) ellipsis in the $(\delta)$ clause before (you) .

(6) $\mid(\alpha)$ Batlalso wants to be recognized $\|(\beta)$ <as the guy $\|(\gamma)$ who got Steve

(as the guy) is an enhancement of finite causal- conditional clause and it is enclosed between brackets because it also defines (Batlalso ) which is also 
أبحاث المؤتمر العلمي الدولي الثاني / نقابة

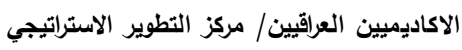

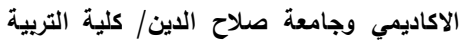

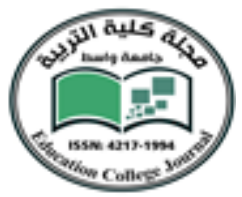

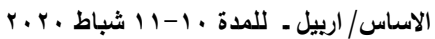

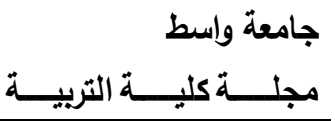

defined by $(\gamma)$ clause, who got Steve Ballmer to dropped out of...is a relative clause showing elaboration, we have two types of expansion: enhancement and a shift to elaboration to draw the attention to who Batlalso is .

(7) $\mid(\alpha)$ We clung to each other $\|(\beta)$ as a way of valid at ingour rejection $\|(\gamma)$ of all those social people ।

(as) is a subordination showing that the $(\beta)$ clause is in an enhancement relationship with the $(\alpha)$ clause .It is a finite clause (as) is showing causal conditional relation.

(8) $\mid(\alpha)$ One of my biggest memories came in January $1975 \|(\beta)$ when I made a call from Currier House $\|(\gamma)$ to company in Abuquerque $\|(\delta)$ that had begun making the world first personal computers|

$(\beta)$ is an enhancement semantic relationship showing temporal relation of (same time) category .It is a non - finite clause, the $(\delta)$ clause is a relative one expresses elaboration identifying the noun precedes it( the company) to take the listener 's attention to this noun (which company?).

(9) $\mid(\alpha)$ There were intervention $\|(\beta)$ that could save lives $\|(\gamma)$ that just weren't being delivered I

The ( $\beta$ ) clause defines the noun (intervention) and it is an elaboration relationship .The next dependent clause $(\gamma)$ defines the noun (lives ), is also elaboration.

(10) I( $\beta)$ If you believe $\|(\gamma)$ that every life has equal value $\|(\alpha)$ its revolting to learn $\|(\delta)$ that some lives are seen $\|(\grave{\varepsilon})$ as worth saving and others are notl

The $(\beta)$ clause comes first showing an extension (alternation) relationship it is called the negative condition the $(\gamma)$ clause is a relative expresses elaboration , $(\delta)$ the subordinator (as) is an enhancing relationship a finite clause with manner (comparison) category .The speaker here has an important theme and he wants the audience to pay a special attention to it too. 
أبحاث المؤتمر العلمي الدولي الثاني / نقابة

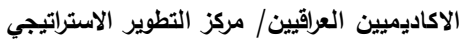

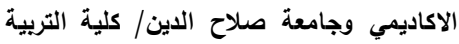

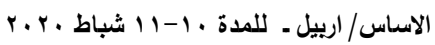

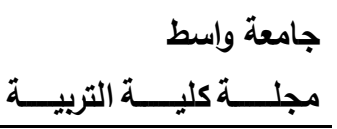

\section{Results}

Here are tables showing the frequency of each type of the logico semantic relations in each speech,

\begin{tabular}{|l|l|l|}
\hline Type of relationship & Sub types & Frequency \\
\hline Expantion & Elaboration & $32 \%$ \\
\hline & Enhancement & $48 \%$ \\
\hline & Extension & $4 \%$ \\
\hline Projection & & $6 \%$ \\
\hline $\begin{array}{l}\text { Total no.of analyized } \\
\text { subordinating clauses }\end{array}$ & 126 & $100 \%$ \\
\hline
\end{tabular}

Frequency of subordinating relations in Steve Jobs 's speech Table(1)

\begin{tabular}{|l|l|l|}
\hline Type of relationship & Sub type & Frequency \\
\hline Expansion & Elaboration & $59.3 \%$ \\
\hline & Enhancement & $26,1 \%$ \\
\hline & Extension & $3.18 \%$ \\
\hline Projection & & $13.37 \%$ \\
\hline $\begin{array}{l}\text { Total no.of analyzed } \\
\text { clauses }\end{array}$ & 157 & $100 \%$ \\
\hline
\end{tabular}

Frequency of subordinating relations in Bill Gates's speechs(Table2)

From the tables above we notice that the rate of each type of relation in each speeches is very close to the rate of each type in the other speech. The following is a table showing the total frequencies of the relationships in both speeches,

\begin{tabular}{|l|l|l|}
\hline Types of relations & Sub types & frequency \\
\hline Expansion & Elaboration & $45.9 \%$ \\
\hline & Enhancement & $36 \%$ \\
\hline & Extension & $3.5 \%$ \\
\hline Projection & & $14.4 \%$ \\
\hline $\begin{array}{l}\text { Total no.of subordinating } \\
\text { clauses }\end{array}$ & 283 & $100 \%$ \\
\hline
\end{tabular}

Table (3) 
أبحاث المؤتمر العلمي الدولي الثاني / نقابة

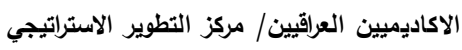

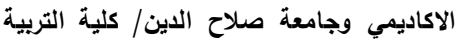

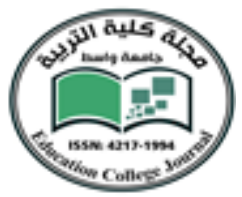

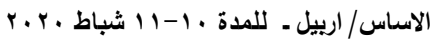

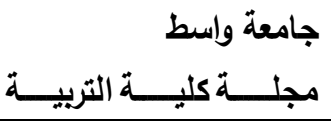

Discussion of the Results

The number of subordinating analyzed clauses in both speeches is(283) clauses classified as Expansion and projection clauses. Expansion gives a special effect on speeches compared with the other types of relations in giving the wanted result related to its nature .This shows the importance of using subordination in building a strong text, and in clarifying ideas speakers and writers need frequently to mix their language with a lot of conjunctions .

\section{Conclusion}

To conclude, this paper has demonstrated what is called logical relations between clauses in speeches of two of the most famous figures in the world . In their speeches, we find that they used binders and certain strategies to connect their clauses and ideas so they increase the frequency with which they construe logical relations generally - under these they made their texts more "heteroglossic". Subordinating as a device used in texts to hang bits of information together in order to create coherent texts ,by using subordination and a subordinating conjunction it establishes the relationship between the dependent clause and the rest of the sentence .The the analysis revealed that subordination plays a big role in building text meaning. Subordinating is another means of communicating more than one idea in a stretch of language . Independent and dependent ideas are usually conveyed as one. Speakers need to have the influence by the selection of the language they use to convey their thoughts and their purpose to their audiences .Among the types of logico relations ,expansion and especially elaboration is used over projection and this is because of the nature of their texts and the purpose of their speeches ,So this type is the most appropriate one ,for them ,to make the impact they want from their words . 
أبحاث المؤتمر العلمي الدولي الثاني / نقابة

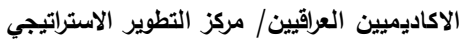

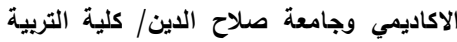

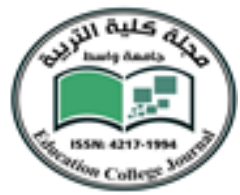

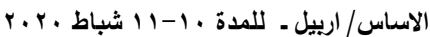

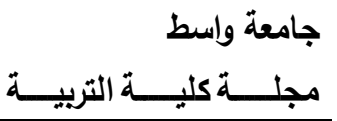

\section{References}

Alexander ,L.G. Longman English Grammar practice for intermediate students . London:longman,1990

Altenberg,Evelyn and P.;Robert M. Vago English Grammar:understanding the Basics.London : Cambridge university Press,2010

Chafe ,L.W.(ed)The Pear stories :Cognitive, Cultural and linguistic Aspect of Narrative Production.Noowood,N.J.;Ablex publishing corp,1980

Collins,Peter C. Cleft and Pseudo -Cleft Constructions_in English_London: Longman,1991

Eggins,S.An Introduction to Systematic FunctionalLinguistics.(2nd edition) London:Longman ,2004

Fish,Stanley How to Write a Sentence and how to read one .London : Longman,2011

Greenbaum,S.and Gerald Nelson (2nd edition) An Introduction to English Grammar.London:Longman,2002

Halliday,M.A.K.and C.Matthiessen (3rd edition) An Introduction to functional Grammar.New York: Hodder Headline Group,2004

Hasselgard, H. Ajunct Adverbials in English .NewYork:Cambridge. 2010

Huddleston,G.and Geoffrey K. Pullum Student Introduction to Grammar. New York:Cambridge,2005

Morley G. David Syntax in Functional Grammar:An Intrduction to Lexicogrammar In_systemic linguistics.London:Contiuum,2000

Parrott,Martin (2nd edition) Grammar for English Language_Teachers. New York: Cambridge, 2000

Quirk,R.,S.Greenbaum.,G.Leech,\& J.Svartivk.A Comprehesive Grammar of the English_Language .London : Longman, 1985 A Comprehensive Grammar of the English_Language.London : Longman,1960

\section{Internet Video sources :}

https://www.youtube.com/watch?v=UF8uR6Z6KLc

https://www.youtube.com/watch?v=zPx5N6Lh3sw 